\title{
An Actor-Partner Interdependence Model on Family Resilience and Subjective Wellbeing
}

\author{
Anna H. C. Neo1, Weining C. Chang2, Daniel S. S. Fung ${ }^{3}$ \\ ${ }^{1}$ Nanyang Technological University, Singapore City, Singapore \\ ${ }^{2}$ Duke-National University of Singapore Graduate Medical School, Singapore City, Singapore \\ ${ }^{3}$ Institute of Mental Health, Singapore City, Singapore \\ Email: weiningc@earthlink.net
}

Received 6 May 2016; accepted 19 June 2016; published 22 June 2016

Copyright (C) 2016 by authors and Scientific Research Publishing Inc.

This work is licensed under the Creative Commons Attribution International License (CC BY).

http://creativecommons.org/licenses/by/4.0/

(c) (i)

Open Access

\section{Abstract}

In times of crisis the family often react together as a unit of response, as though a combat unit. The concept of family resilience has been identified as a coping resource for the family unit even if the crisis affected only one individual of the family. Family resilience works in concert with individual psychological resilience to protect the individual from excess negative impact and to improve positive outcomes such as subjective wellbeing. However, the impact of family resilience on the adaptive outcome is far more complex than individual resilience. The present study aims to identify the internal dynamics between the individual actor and her familial partner, using the Actor-Partner Interdependence Model. A total of $\mathbf{3 8}$ family dyads, each pair consisted of a hospital nurse and one of her family members participated in the present study. Among them are 49 females and 27 males, with mean age of $\mathbf{4 0 . 6 2}$ years old. The nurses were recruited from two major public hospitals that admitted patients and patients suspected of being infected with an infectious disease during a pandemic out-break. The family members were 2 parents, 24 spouse, 6 siblings, and 6 children of the nurses. Main effects of actor's resilience and partner's resilience, as well as interaction effect between actor's and partner's resilience, on actor's subjective wellbeing, were found. This suggests interdependence effects of individual's resilience and the other party's wellbeing. Results indicated that the 1) the multifaceted-multi-processed family resilience affects the individual outcomes in different ways: Family resilience of familial process and function showed only actor effect on individual subjective wellbeing, family resilience of shared beliefs and emotional regulation however showed actor and partner effects and with the partner showed higher effect. 2) The hypothesis on interdependence effects was supported for the family resilience dimensions of meaning-making and emotional regulation.

\section{Keywords}

Family Resilience, Stress-and-Coping, Subjective Wellbeing, Actor-Partner Interdependence 


\section{Model}

\section{Introduction/Rationale-An Actor-Partner Interdependence Model on Family Resilience and Subjective Wellbeing}

Psychological resilience is the dynamic process of adaptation that arises in adversity, enables the individual to thrive, and emerges from the crisis being reassured or even strengthened. In other words, psychological resilience moderates the stress-and-coping process, and contributes to the coping outcome. Family resilience, a family level construct, reduces negative impact and promotes the likelihood for adaptive responses (Chang, Neo, \& Fung, 2015; Cowan, Cowan \& Schulz, 1996) of the family system (Walsh, 2002).

At the individual level, psychological resilience is often examined as a personal asset and treated as a construct made of a personality trait or a cluster of traits and processes. Recent research has started to recognize the social and contextual resources (Bronfenbrenner, 2009) that empower the individual in times of crisis. Researchers and practitioners alike call for culturally relevant research to develop appropriate intervention programs that enhance children's psychological resilience (for instance, Todd et al., 2012). A poignant recent study found that reading culturally relevant stories to child orphaned by AIDS enhanced the children's resilience (Wood, Theron, \& Mayaba, 2012). The family has been seen as one of the major sources for individuals encountering threatening events.

The human family is a complex and open system. Research studies have employed different levels of analysis to approach the family: the individual level, the relationship or dyadic level (e.g., couples, parent-child, and siblings) within the family and the (whole) family level. At each level, there might be different mechanisms that govern the functioning of the family; at different levels, the dynamics between the environmental challenges and coping reactions could lead to different outcomes. Positive and negative family outcomes, in turn, deferentially impact the individual, the relationships within the family and the family itself.

Early literatures on family strengths are largely limited to developmental studies focusing on psychopathological issues (e.g., Rutter, 1990), and pitching the individual against the family. The focus of these studies is often on exploring how an individual thrives in dysfunctional families and impaired relationships, rather than how the stressed families successfully cope with the crisis (Walsh, 2015). Such studies attended to the family deficit, disregard the capabilities of the family and within family relationships in building and sustaining resilience in the individual. In contrast, the contemporary focus of family studies views the family in-crisis as being challenged or tested, that the family might in respond to the challenge and actively manages the impact of the crisis, rather than being passively "hit" and injured by the crisis. In this, the family is seen as a dynamic organism that has the capacity for responding, renewal and restoration, therefore, there is "resilience" at the family level and the family and the individuals within it are not always at odds with each other.

Family as a complex and open system, when a crisis is directly experienced by a family member, the wellbeing and adjustment of all individuals within the family depends on the ongoing negotiation between the vulnerability caused by the stressful events encountered, and the shielding and safeguarding mechanism afforded by the family (De Hann, Hawley, \& Deal, 2002). It, therefore, naturally follows that the family and the individual's welfare and resilience are mutually affecting each other (Parchment, Small, Osuji, McKay, \& Bhana, 2016). In studies of families living in vulnerable contexts such as poverty or displacement, family resilience provides protection and empowerment to improve children's resilience and welfare (Usamah, Handmer, Michelll, \& Ahmed, 2014).

Resilience at the family level has been found to be a different construct than the sum of individual psychological resilience. In an interview study on how Singaporean nurses had coped with the 2003 SARS outbreak, it was observed frequently from their qualitative reports that they have coped with the crisis together as a family (Chang, Neo, \& Fung, 2015). From this study, a Family Resilience Scale (FRS) was developed to represent the conceptualization and manifestation of resilience at the family level. The FRS quantitatively assesses the degree to which a family is resilient in the face of challenges. The study further tested the relationship between FRS and individual psychological resilience and found that the FRS is indeed a non-spurious variable from individual resilience.

Within the family and cross levels, psychological resilience is affected by the relational context in which the 
individual is embedded. This relational context, in turn, influences the way in which, the person views and approaches the challenging situation (Walsh, 1996, 2015) and produces differential outcomes for adaptation. For instance, children in Hawaii who grew up as resilient adults were found to have close and positive relationships with at least one of the family members, as compared to children without positive family relationships (Simon, Murphy, \& Smith, 2005).

The current paper evaluates the internal dynamics of the family, at the relational level, along the family resilience construct.

As the family system theory (Broderick, 1993) observed, within the family, interdependence is forged in reciprocal relationships between family members. Members within the family influence each other's thoughts, feelings, and behaviors (Rayens \& Svavarsdottir, 2003). Consequently, whatever that influences the individual in the family will naturally affect the other members in the system (Segrin et al., 2005).

Family research across various fields has found much similarity and overlap of the basic elements constituting the key processes of being a resilient family (Lee et al., 2004). Walsh (2003: p. 405) summarized the main characteristics of family resilience as "family belief system, organization patterns and communication processes". Walsh emphasized the importance for family to have shared beliefs and a constructive system which enable family members to view and approach the stressful event positively with a proactive stance. The family could redefine and "normalize" the distressing situation, and adopt a collective positive outlook. At the same time, being a united family that accommodates and cooperates with other family members, building connections through commitment and effective communication with appropriate emotional expressions are also essential to a resilient family. These components are consistent with the dimensions of family resilience found in the Chang, Neo \& Fung's (2015) Singapore study. The FRS dimensions are 1) Family solidarity (i.e., family connectedness, unity and flexibility), 2) Meaning-making (i.e., redefine the meaning of adversity and approach accordingly), 3) Religiosity, 4) Emotional Regulation (i.e., the control of emotional expression), whereby family solidarity and emotional control coincides with the component of "family organization and communication" regarding the unity and connectedness of the family found across many studies; while meaning-making and religiosity correspond with the "family belief systems" as summarized by Walsh $(1996,2003)$.

Contemporary family literature, especially the theory proposed by Antonovsky and Sourani (1988) further recognize that shared cognitive factors such as positive interpretation and shared meanings of stressful events help the individual and the family to gain a "coherence" of the family and the challenging event. The shared construction of the reality would promote family solidarity and facilitate positive adaptation of the family and the individual. Family and the resilience of the family are thus seen as joint products, collectively constructed by the interacting members. This approach is in contrast to the traditional approach that views family resilience as the aggregate of independent individual members (Simon, Murphy, \& Smith, 2005). These studies failed to assess the family unit itself, nor account for the interdependency between members within the family. The resilient family, on the other hand, might perceive the crisis situation as a "shared challenge" (p. 407), and draws their combined strength from their solidarity with their family members.

Finally, it is noted that resilience is often observed at the time of crises and in responses to adversity. Being a resilient family is not being unaffected by the stressful conditions, but is able to confront and adapt to the difficult situation positively (Cowan et al., 1996). In other words, the resilient family does not avoid the crisis, but manage it together as a "team", and rebound from it, transforming into a stronger and more cohesive family. This perspective suggests that it is not the sum total of individual resilience but the extent to which the family members have shared meaning of the crisis and the family situation that brings resilience. Assessing family resilience by taking the family as a unit is relatively scarce in family research; research addressing internal dyadic relationships is even more lacking. The current study, therefore, proposes to address two main questions: 1) Are there reciprocal influences between family members on their perception of the family resilience, and 2) Would the family with members having shared perception of the family have better psychological adjustments?

From the ecological system framework, the human family is a collection of interpersonal communication units-or relationship units. The family levels of functioning depends on the interpersonal communication within the family. The family is therefore, a construct built on the perceptions of the members and the constituent relationships within the family. How the family unit influences its members and vice versa therefore, hinges on the dynamic communications within members of the family unit. According to the family systems theory, members within the family influence each other's thoughts, feelings, and behaviors (Rayens \& Svavarsdottir, 2003). Consequently, whatever happens to one individual would inevitably influence the welfare of others within the family (Segrin et al., 2005). One member's emotional state and cognition would influence the feelings and 
cognitions of other members who interact with her on a regular basis. For instance, couples were found to be similar in the severity of their depression symptoms (Westman \& Vinokur, 1998). Hence it is important to understand the relational dynamics within the family.

We propose to study family resilience and its effects by employing dyads within the family as the unit of analysis, and attempt to understand the interaction within the dyad on family resilience and psychological wellbeing.

\section{Actor-Partner Interdependence Model}

The Actor-Partner Interdependence Model (Kashy \& Kenny, 1999; Kenny \& Cook, 1999) has been utilized to analyze the dyadic data. It is a statistical estimation model for dyadic relationships that allow direct examination at the dyad level, as well as the actor and partner effects (see Figure 1). The $X$ and $X^{\prime}$, in the present study are the family resilience scores for the two family members, while $\mathrm{Y}$ and $\mathrm{Y}$ ' are the subjective wellbeing scores of the two family members respectively. Actor effect refers to the direct effect of a person's predictor score on her/his own outcome scores while controlling for the partner effects (i.e. Path A in Figure 1). Partner effect is the direct modeling of the interdependence present within the dyad (i.e., Path P in Figure 1). It estimates the effect of a person's predictor scores on his or her partner's outcome scores, while controlling for the actor effects and vice versa. The presence of partner effect would denote the partners in the dyad are interdependent.

\section{The Present Study}

The Actor-Partner Interdependence Model approach was applied to the present study to examine the effects of perceived family resilience on individuals' psychological wellbeing. From a systemic view, the crisis event impacts the whole family and it is through the family members' dynamic interaction and collaborative efforts that build and restore the family from the distressing experiences. In this way, the members influence each other during their transitions and growth in dealing with the hardship (Walsh, 2003). Hence it is hypothesized that there is actor and partner effects for the four dimensions of family resilience (i.e., family solidarity, meaning-making, religiosity and emotional regulation) on subjective wellbeing, in that higher perceived resilience in the individual, would predict higher scores on his or her own subjective wellbeing, as well as his or her partner's subjective wellbeing.

Researchers have contended that the understanding or coherence perceptions regarding the family (e.g., family values, family identity, life challenges, worldview etc.) is inherent to family resilience, the shared meanings may assist the family to adjust their familial resources in a more efficient way that enhances resilience (Patterson \& Garwick, 1998; Walsh, 2003). Thus, the data will be used to explore the combinations of different levels of family resilience among the family dyads that is beneficial to the individual's wellbeing. That is, whether the family members serve complementary functions or whether similar mind-sets regarding family strengths is more beneficial to all members of the family. In any case, the effect of actor resilience scores on his or her subjective wellbeing is dependent on the resilience scores of the partner's and vice versa. Hence it is hypothesized that there is actor-partner interaction effect for family resilience (i.e., family solidarity, meaning-making, religious faith and emotional regulation) on subjective well-being.

The current study also aims to investigate whether the different types of familial relationships have impact on how the individuals perceive family resilience that influences their adjustments. Thus, relationship types (spousal or non-spousal relationships) were added to the model as a dyad-level variable. Non-spousal relationships

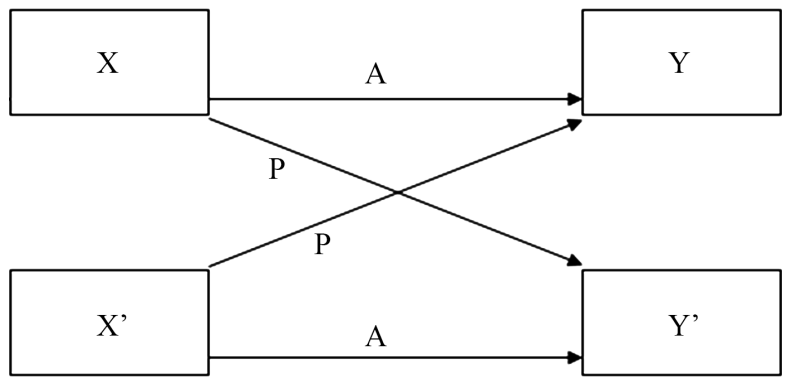

Figure 1. The simplified actor-partner interdependence model (adapted from Cook \& Kenny, 2005). 
within the family (i.e., parent-child, siblings, etc.) are relatively more hierarchical than spousal relationships (e.g., Fuligni \& Zhang, 2004; Goodwin \& Tang, 1996). It is expected that non-spousal relationships (i.e., parentchild, and siblings) and spousal relationship might differ in their association between family resilience and subjective wellbeing.

\section{Method}

\subsection{Participants}

The current study employed a sample of family dyads made of nurses and their family members that were exposed to SARS.

A total of 38 family dyads, each pair consisted of a hospital nurse and one of her family members, participated in the present study. Among them are 49 females and 27 males, with mean age of 40.62 years old. The nurses were recruited from two Singapore hospitals that had admitted SARS patients and patients suspected of infecting with SARS during a pandemic outbreak (i.e., Singapore General Hospital and Tan Tock Seng Hospital). The family members were 2 parents, 24 spouse, 6 siblings, and 6 children of the nurses. There were 54 Chinese, 12 Malays and 10 Indians. Thirty of the participants were Christians or Catholics, 13 were Buddhists or Taoist, 14 were Muslims, 6 were Hindus, and 13 did not indicate any religious beliefs.

\subsection{Measures}

There were a total of two English/Chinese paper-and-pencil questionnaires (see Appendix). These questionnaires were: 1) Family Resilience Scale (Chang, Neo, \& Fung, 2015); 2) Abbreviated 15-items Asian Subjective Well-being (Chang, 2003). The following section provides detailed descriptions of each of the questionnaires used Family Resilience Scale (Chang, Neo, \& Fung, 2015).

The Family Resilience Scale was constructed from information obtained from a series of qualitative interviews of 30 nurses from a major public hospital in Singapore. This 19-items questionnaire was used to assess how families deal with adversity, as perceived by the individual. There were four factors within the scale: 1) Family Solidarity (consisted of 10 items), 2) Meaning-making (consisted of 4 items) and 3) Religiosity (consisted of 2 items), and 4) Emotional Regulation (consisted of 3 items). The Family Solidarity factor assesses within-family connectedness and unity as perceived by the individuals (e.g., "we accommodate to one another's need", "we have a good communication within the family" etc.). The Meaning-making factor taps into the family belief systems on how the family defines and deals with adversity (e.g., "we accept the situation", "we make the situation as normal as possible" etc). The Religiosity factor measures the family's adherence to religious belief in helping them to deal with the stressful situation (e.g., "we believe in God"). The Emotional Regulation factor assesses the family's regulatory efforts on emotional expressions within the family (e.g., "We control negative emotions"). Respondents were required to indicate to what extent they agree or disagree with each statement, using a five-point Likert scale, ranging from " 1 " Strongly Disagree to " 5 " Strongly Agree". Higher score would indicate higher level of resilience in the family as perceived by the individual. The reliability alpha obtained for the present study is ranged from to 0.40 to 0.91 across the four sub-scales.

\subsection{Asian Subjective Well-Being (Chang, 2003)}

This is an abbreviated 15-items version of the initial 30 items scale (Chu, 2002), obtained by performing split-half reliability (alpha $=0.90$ ) on the original scale. Asian Subjective Well-being measures how much a person thinks he or she is happy and satisfied with his or her life (e.g., "I am having a balanced life"). Respondents were required to indicate the extent to which each statement describes their current state on a 5-point scale, ranging from "doesn't describe me at all" to "describe me very much". The initial 30-items scale reported having two factors with alpha of 0.92 to 0.81 for individual well-being factor and family well-being factor respectively. The 15-items version used in current study transformed the initial short phrases items into full sentence items. The reliability alpha obtained for the present study is 0.93 .

\subsection{Procedures}

The participants were nurses recruited from two Singapore hospitals that housed pandemic-affected patients. 
The questionnaires were sent to the nurses via the nursing administration department in the respective hospitals. The questionnaires were packed into envelopes and delivered to nurses who consented to take part in the study. In each envelope, there are two sets of the same questionnaires. The nurses were required to fill in one set of the questionnaires by themselves, and asked one of her family members to fill in the other set of questionnaires. The family members recruited can be spouse of the nurse, child of the nurse or parent of the nurse. Upon completing the questionnaires, they were requested to return the questionnaires in sealed envelope to us via the nursing administration department of their working hospitals.

\section{Results}

\subsection{Test for Interdependence}

An intraclass correlation (ICC) was computed to examine the degree of interdependence on the outcome variable, subjective wellbeing. The ICC obtained was 0.39 , which is higher than 0.20 , suggesting the use of multilevel modeling with Actor-Partner Interdependence Model (APIM) to be an appropriate approach for the present study, taking into consideration the interdependence of data.

\subsection{APIM Analysis}

There are several proposed methods to analyze APIM. The current study utilized the multi-level modeling technique, which is one of the relatively straightforward techniques as compared to pooled multiple regressions and structural equation modeling. The present study followed the two-stage procedures of analyzing APIM laid out by Cook and Snyder (2005), starting with estimating main effects model and followed by testing moderation effects.

\subsection{Main Effect Analyses}

Results of APIM analyses via multilevel modeling for the main effects were presented in Table 1 and Table 2. There are two main effect models tested: The first main effect model consisted of variables in the family resilience dimensions that correspond to Walsh's conception of "family organizational patterns and communication”: the actor and partner scores for Family Solidarity factor, and actor and partner scores for Emotional Regulation factor. The next main effects model tested comprised of the family resilience dimensions that correspond to Walsh's notion of “family beliefs systems" which includes the actor and partner scores for meaning-making, and the actor and partner scores for religious faith. There is a level 2 predictor in both main effects models: type of relationships, which is effect-coded as 1 and -1 for spousal and non-spousal relationships respectively. Results (see Table 1) revealed that the actor main effect for family solidarity and emotional regulation significantly predicted the individuals' subjective wellbeing. Neither partner effect for family solidarity and emotional regulation were significant. There was also no significant effect for the type of relationships in the family on subjective wellbeing.

For the family resilience dimensions falling under "family belief systems", both the actor and partner effects for meaning-making was statistically significant; while only partner effect was significant for religious faith (see Table 2).

The main effect analysis for "family organizational patterns and communications" found positive actor effects ( $\beta=0.25, p=0.048$ ) for family solidarity, which suggests that individuals who perceived their family being united and cohesive under stressful situations would have higher subjective wellbeing, holding all other predictor variables constant. However, there is no significant partner effect for family solidarity. Similarly, the positive actor effects for emotional regulation indicated that individual would have higher subjective wellbeing when he or she perceived the family capabilities in controlling and regulating emotional expressions in stressful conditions, holding all other effects constant.

For the "family belief systems" main effects analysis, positive partner effect $(\beta=0.20, p=0.013)$ for religiosity found indicated that the individual would have higher subjective wellbeing if their partner (i.e., the family member in the dyad) adhered more strongly to their religious faith when dealing with hardships, holding all other variables constant. The significant actor effect $(\beta=0.29, p=0.027)$ of meaning-making dimensions indicated that a person's perception of shared meaning-making within the family predicted the person's subjective wellbeing, with higher perceived resilience resulted in higher subjective wellbeing, holding the other effects constant. 
Table 1. Main effects results: Family organizational patterns and communications.

\begin{tabular}{ccccc}
\hline Variable & $\beta$ & $S E$ & $d f$ & $p$ \\
\hline Family Solidarity & & & & \\
Actor & 0.25 & 0.12 & 64.61 & $0.048^{*}$ \\
Partner & 0.07 & 0.12 & 64.61 & 0.585 \\
Emotional Regulation & & & & \\
Actor & 0.34 & 0.12 & 69.22 & $0.008^{* *}$ \\
Partner & 0.10 & 0.12 & 69.22 & 0.424 \\
Relationship Condition & -0.07 & 0.06 & 34.00 & 0.378 \\
\hline${ }^{*} p<0.05,{ }^{* *} p<0.01$. & & &
\end{tabular}

Table 2. Main effects results: Family beliefs systems.

\begin{tabular}{ccccc}
\hline Variable & $\beta$ & $S E$ & $d f$ & $p$ \\
Meaning Making & & & & \\
Actor & 0.29 & 0.09 & 70.00 & $0.002^{*}$ \\
Partner & 0.18 & 0.09 & 70.00 & $0.057^{+}$ \\
Religious Faith & & & \\
Actor & -0.06 & 0.09 & 50.21 & 0.468 \\
Partner & 0.20 & 0.09 & 50.21 & $0.025^{*}$ \\
Relationship Condition $^{*} p<0.05,{ }^{+} p<0.10$. & -0.06 & 0.07 & 34.00 & 0.433 \\
\hline
\end{tabular}

There was also a marginally significant partner effect $(\beta=0.18, p=0.057)$ for meaning-making, suggesting the mutual influence between the members in the dyad, such that a person's meaning-making scores predicted his or her partner's subjective wellbeing and vice versa.

The type of relationship was not significant for both actor and partner effects, suggesting that there is no difference between spousal and non-spousal relationships in the association between perceived family resilience and subjective wellbeing.

\subsection{Interactions: Coherent Perceptions of Resilience within the Family}

One of the main aims of the study was to examine whether having shared perceptions in factors that constitute family resilience would help the individuals to be better-adjusted, resulting in higher subjective wellbeing. Thus, new interaction terms for individual factors of family resilience need to be computed by multiplying the grandmean-centered-actor and grand-mean-centered-partner scores for the respective resilience factors. For instance, for family solidarity, an interaction term for actor's and partner's family solidarity score computed would be:

Actor's family solidarity $\times$ Partner's family solidarity = AP_family solidarity

The new interaction model for each resilience factor would include the actor's and partner's main effects for that particular resilience factor, as well as the new interaction term. The same analysis will be repeated for each of the resilience factors separately. Results are summarized in Table 3.

Results showed that the actor-partner interaction for meaning-making factor of family resilience is significant, after controlling for the actor and partner main effects. Thus the hypothesis of interaction effect between actor and partner for family resilience was supported in the meaning-making dimensions, suggesting that the association between a person's subjective wellbeing and meaning-making of the adversity varies as a function of the partner's level of meaning-making. The negative coefficient $(\beta=-0.31, p=0.044)$ indicated that within the family dyad, one would have lower subjective wellbeing when one person is above average in meaning-making 
while the other person is below average in meaning-making, after controlling for the main effects. This is demonstrated in Figure 2, whereby higher levels of subjective wellbeing were reported when the actors have higher perceived resilience (in terms of meaning-making) and especially when the partner also perceived higher resilience in meaning-making factor. This suggest that family resilience in terms of making sense of the adversity and adopting a positive outlook would require family members within the dyad to have similar perceptions to it.

The actor-partner interaction effect for emotional regulation was significant after controlling for the actor and partner main effects in emotional regulation. The significant results suggested that the negative association between a person's subjective wellbeing and perceived family's emotional regulation varies as a function of the partner's perceived level of family's emotional regulation. Figure 3 showed that higher subjective wellbeing

Table 3. Actor-partner interaction model results.

\begin{tabular}{ccccc}
\hline Variable & $\beta$ & $S E$ & $d f$ & $p$ \\
\hline Family Solidarity & -0.34 & 0.23 & 35.00 & 0.146 \\
Meaning Making & -0.31 & 0.15 & 35.00 & $0.044^{*}$ \\
Religious Faith & 0.08 & 0.06 & 35.00 & 0.233 \\
Emotional Regulation & -0.56 & 0.25 & 35.00 & $0.031^{*}$ \\
\hline
\end{tabular}

${ }^{*} p<0.05,{ }^{+} p<0.10$.

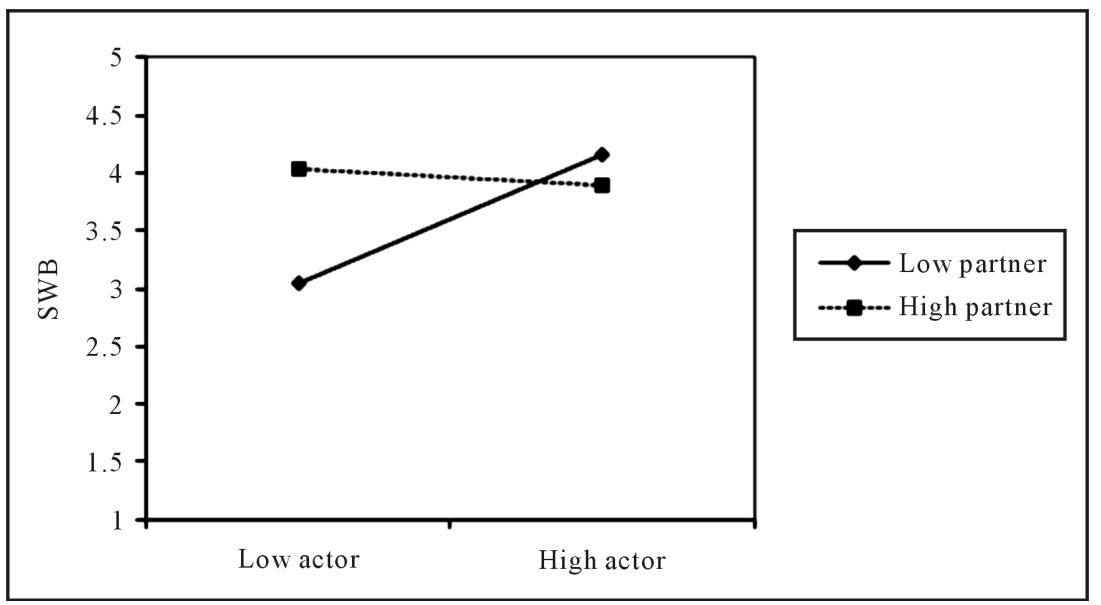

Figure 2. Actor-partner interaction effect for meaning-making.

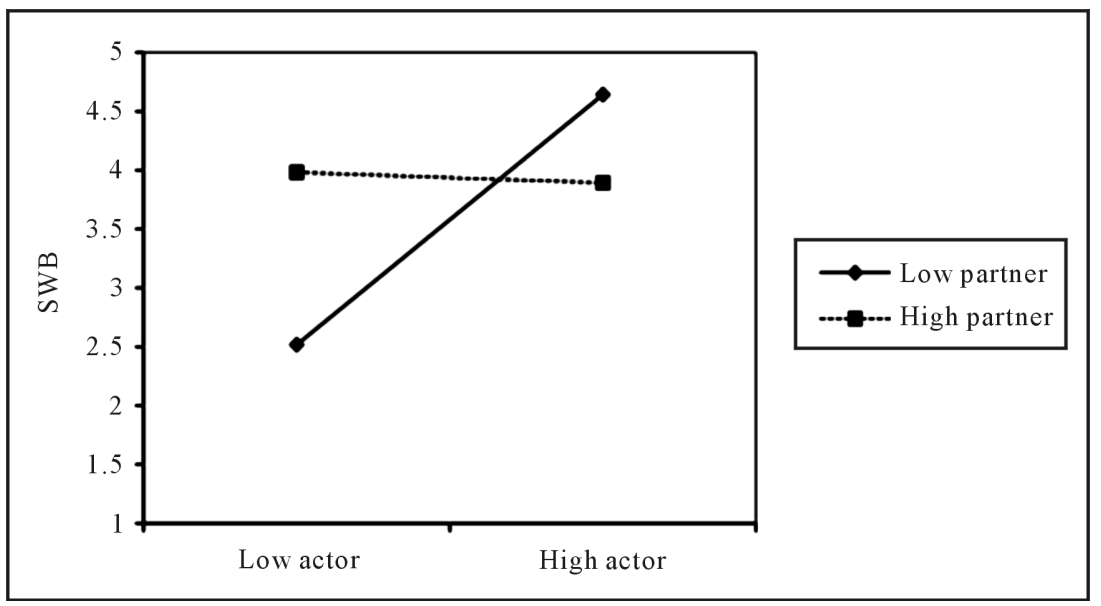

Figure 3. Actor-partner interaction effect for emotional regulation. 
was reported when actor perceived higher resilience (in emotional regulation factor), and especially when the partner perceived higher resilience (in emotional regulation factor).

\section{Discussion}

Family resilience is relevant to and has important impact on a person's adaptive adjustment as reflected in its effects on the family member's subjective wellbeing. The present study found that reciprocal influence of perceived family resilience exists among the members of the family dyads, in the dimensions of meaning-making and religiosity, which are components of the "family beliefs systems". More importantly, the present study showed that in both meaning-making and emotional regulation, the level of subjective wellbeing differs for the family dyads that have different combinations of perceived family resilience.

\subsection{Actor and Partner Main Effects}

The direct impact of a person's perceived family resilience on his or her own subjective wellbeing was observed on family resilience factors that are critical to the organization patterns and communications (Walsh, 2003), such as family solidarity and emotional regulation. Furthermore, the higher a person perceived family solidarity and emotional regulation, the higher the person's subjective wellbeing. This is consistent with the general notion that family resilience provides resources that helps an individual to cope effectively with difficulty in life; through effective coping the person transforms and emerges with a clearer sense of purpose and hardiness (Walsh, 2003).

The interdependence between members in the family dyads was modeled by the partner effects; significant effects were found for meaning-making and religiosity. These are the family resilience dimensions that are essential to the "family beliefs systems" discussed earlier. It is not difficult to understand why significant mutual influence was found in dimensions related to "family beliefs systems" rather than the "family organizational patterns and communications". When a crisis happens, the first impact would be on the family: Crisis encountered demands a reshuffling of priorities and daily functions of the family. Hence, the shared beliefs and the attempts to make sense of the stressful condition, formed the cognitive basis or a meaningful framework for the family to work together to re-organize itself and to direct the interactional process (Walsh, 2003). A sense of coherence within the family, building upon shared meaning and beliefs, would empower family members to view adversity as a challenge and an opportunity for further growth (Antonovsky \& Sourani, 1988). With this shared positive framework of meaning, the family learns to "normalize" the situation (i.e. accept the situation and live as normal as possible), and reduce negative emotions. This positive sense of coherence would lay the foundation for family unity and cohesion.

\subsection{Interaction Effects}

The hypothesis on interaction effects was supported for the dimensions of meaning-making and emotional regulation. The different combinations of perceived family resilience may have important clinical implications. Clinicians working with the family system should be informed whether congruent perceptions or complementary perceptions of what makes their family strong is beneficial to a person's wellbeing and devised preventive programs that keep the family in the optimal patterns of functioning. From these results we can see that both the "family belief systems" and "family organizational patterns and communications" requires coherent beliefs among the family dyads to have a positive impact on individuals' subjective wellbeing.

It is expected that stress would be intensified when partners involved in intimate relationships have different degrees of endorsement of the beliefs on fundamental issues. Supporting this, the interaction effect on meaningmaking showed that congruent mindsets whereby both partners are high in meaning making, helps the family to stay resilient as shown by the impact on family members' subjective wellbeing. Similarly, the negative interaction effect obtained between actor and partner effects of emotional regulation on subjective wellbeing suggested that there will be a negative impact on subjective wellbeing if one member engaged in high emotional regulation while the other have low emotional regulation. These results highlighted the importance of coherence among family members rather than complementary functions in dealing with emotional distress during time of crises. Each culture has its own display rules concerning emotion expression. This is especially relevant to collectivistic Chinese families where suppressing negative feelings is highly emphasized within the culture, for fear of disrupting the peace and harmony of the family (Fitness, 2013). It is often questioned whether such suppression 
actually hinders the meaning making effort of the family that might lead to coherence. Future studies should be conducted to address this question and the potential causal relationships between emotional regulation and meaning making processes within the family in different cultural contexts.

\subsection{Limitations and Future Research}

One limitation of the present study is that the effects observed are restricted to dyadic pairs within the family. The dynamics of family resilience might be different when all members of the family are taken into consideration, but the present data set could not look into the influences among family members beyond the two members. In addition, the current study has only a level 2 or between dyad variable. It is proposed that future studies could explore more of the impact of dyad-level variables have on family members, such as the shared or different religions within the family, the overall economic status of the family and other demographic factors.

Nevertheless, the complicated nature of family resilience makes it a fascinating construct to examine. As more sophisticated statistical strategies and techniques such as APIM to model becomes available, family resilience studies can be expanded to address novel and critical issues. The present study contributes to the family resilience research in the following ways: 1) examining the association between the interdependency among family members and individuals' wellbeing, and 2) identifying the different combinations of specific resilient factors that influence subjective wellbeing.

Future research can explore how family resilience differs in its impact on short term adaptive mechanisms, along with other health and mental health benefits.

\section{References}

Antonovsky, A., \& Sourani, T. (1988). Family Sense of Coherence and Family Adaptation. Journal of Marriage and the Family, 50, 79-92. http://dx.doi.org/10.2307/352429

Broderick, C. B. (1993). Understanding Family Process: Basics of Family Systems Theory. Thousand Oaks, CA: Sage Publications.

Bronfenbrenner, U. (2009). The Ecology of Human Development: Experiments by Nature and Design. Cambridge, MA: Harvard University Press.

Chang, W. C. (2003). Short-Forms Versions of the Asian Subjective Well-Being Scale (Manuscript). Singapore: Department of Social Work and Psychology, National University of Singapore.

Chang, W., Neo, A., \& Fung, D. (2015). In Search of Family Resilience. Psychology, 6, 1594-1607. http://dx.doi.org/10.4236/psych.2015.613157

Cook, W. L., \& Kenny, D. A. (2005). The Actor-Partner Interdependence Model: A Model of Bidirectional Effects in Developmental Studies. International Journal of Behavioral Development, 29, 101-109. http://dx.doi.org/10.1080/01650250444000405

Cook, W. L., \& Snyder, D. K. (2005). Analyzing Nonindependent Outcomes in Couple Therapy Using the Actor-Partner Interdependence Model. Journal of Family Psychology, 19, 133-141. http://dx.doi.org/10.1037/0893-3200.19.1.133

Cowan, P. A., Cowan, C. P., \& Schulz, M. S. (1996). Thinking about Risk and Resilience in Families. In E. M. Hetherington, \& E. A. Blechman (Eds.), Stress, Coping, and Resilience in Children and Families (pp. 1-38). Mahwah, NJ: Erlbaum.

De Hann, L., Hawley, D. R., \& Deal, J. E. (2002). Operationalizing Family Resilience: A Methodological Strategy. The American Journal of Family Therapy, 30, 275-291. http://dx.doi.org/10.1080/01926180290033439

Fitness, J. (2013). The Communication of Emotions in Families. In A. L. Vangelisti (Ed.), The Routledge Handbook of Family Communication (pp.377-390). New York: Routledge.

Fuligni, A. J., \& Zhang, W. (2004). Attitude toward Family Obligation among Adolescents in Contemporary Urban and Rural China. Child Development, 74, 180-192. http://dx.doi.org/10.1111/j.1467-8624.2004.00662.x

Goodwin, R., \& Tang, C. S. (1996). Chinese Personal Relationships. In M. H. Bond (Ed.), The Handbook of Chinese Psychology (pp. 294-308). Hong Kong: Oxford University Press.

Kashy, D. A., \& Kenny, D. A. (1999). The Analysis of Data from Dyads and Groups. In H. T. Reis, \& C. M. Judd (Eds.), Handbook of Research Methods in Social Psychology (pp. 451-477). New York: Cambridge University Press.

Kenny, D. A., \& Cook, W. (1999). Partner Effects in Relationship Research: Conceptual Issues, Analytic Difficulties, and Illustrations. Personal Relationships, 6, 433-448. http://dx.doi.org/10.1111/j.1475-6811.1999.tb00202.X

Lee, I., Lee, E.-O., Kim, H. S., Park, Y. S., Song, M., \& Park, Y. H. (2004). Concept Development of Family Resilience: A Study of Korean Families with a Chronically Ill Child. Journal of Clinical Nursing, 13, 636-645. 
http://dx.doi.org/10.1111/j.1365-2702.2004.00845.x

Parchment, T. M., Small, L., Osuji, H., McKay, M., \& Bhana, A. (2016). Familial and Contextual Influences on Children’s Prosocial Behavior: South African Caregivers as Adult Protective Shields in Enhancing Child Mental Health. Global Social Welfare, 3, 1-10. http://dx.doi.org/10.1007/s40609-016-0042-8

Patterson, J. M., \& Garwick, A. W. (1998). Theoretical Linkages: Family Meanings and Sense of Coherence. In H. I. McCubbin, E. A. Thompson, A. I. Thompson, \& J. E. Fromer (Eds.), Stress, Coping, and Health in Families: Sense of Coherence and Resiliency (pp. 71-90). Thousand Oaks, CA: Sage.

Rayens, M. K., \& Svavarsdottir, E. K. (2003). A New Methodological Approach in Nursing Research: An Actor, Partner, and Interaction Effect Model for Family Outcomes. Research in Nursing and Health, 26, 409-419. http://dx.doi.org/10.1002/nur.10100

Ross, P. (2001). Family Stress Management: A Contextual Approach. Thousand Oaks, CA: Sage.

Rutter, M. (1990). Psychosocial Resilience and Protective Mechanisms. In J. Rolf, A. S. Mastern, D. Cicchetti, K. H. Nuechterlein, \& S. Weintraub (Eds.), Risk and Protective Factors in the Development of Psychopathology (pp. 181-214). Cambridge: Cambridge University Press. http://dx.doi.org/10.1017/CBO9780511752872.013

Segrin, C., Badger, T. A., Meek, P., Lopez, A. M., Bonham, E., \& Sieger, A. (2005). Dyadic Interdependence on Affect and Quality-of-Life Trajectories among Women with Breast Cancer and Their Partners. Journal of Social and Personal Relationships, 22, 673-689. http://dx.doi.org/10.1177/0265407505056443

Simon, J. B., Murphy, J. J., \& Smith, S. M. (2005). Understanding and Fostering Family Resilience. The Family Journal, 13, 427-436. http://dx.doi.org/10.1177/1066480705278724

Todd, C., Macdonald, D., Khoshnood, K., Mansoor, S. F. Eggerman, M., \& Panter-Brick, C. (2012). Opiates Use, Treatment and Harm Reduction in Afghanistan: Recent Changes and Future Directions. Drug Policy, 23, 341-345. http://dx.doi.org/10.1016/j.drugpo.2012.05.004

Usamah, M., Handmer, J., Mitchell, D., \& Ahmed, I. (2014). Can the Vulnerable Be Resilient? Co-Existence of Vulnerability and Disaster Resilience: Informal Settlements in the Philippines. International Journal of Disaster Risk Reduction, 10, 178-189. http://dx.doi.org/10.1016/j.ijdrr.2014.08.007

Walsh, F. (1996). The Concept of Family Resilience: Crisis and Challenge. Family Process, 35, 261-281. http://dx.doi.org/10.1111/j.1545-5300.1996.00261.x

Walsh, F. (2002). A Family Resilience Framework: Innovative Practice Application. Family Relations, 51, $130-137$. http://dx.doi.org/10.1111/j.1741-3729.2002.00130.x

Walsh, F. (2003). Family Resilience: Strengths Forged through Adversity. In F. Walsh (Ed.), Normal Family Processes: Growing Diversity and Complexity (pp. 399-421). New York: The Guilford Press.

Walsh, F. (2015). Strengthening Family Resilience (3rd ed.). New York: The Guilford Press.

Westman, M., \& Vinodur, A. D. (1998). Unraveling the Relationship of Distress Levels Within Couples: Common Stressors, Empathic Reactions, or Crossover via Social Interaction? Human Relations, 51, 137-156. http://dx.doi.org/10.1177/001872679805100202

Wood, L., Theron, L., \& Mayaba, N. (2012). "Read Me to Resilience”: Exploring the Use of Cultural Stories to Boost the Positive Adjustment of Children Orphaned by AIDS. African Journal of AIDS Research, 11, 225-239.

http://dx.doi.org/10.2989/16085906.2012.734982 


\section{Appendix 1}

Family Resilience Scale (Adapted from Chang, Neo, \& Fung, 2015)
1) We make sacrifices for one another
2) We accommodate to one another's needs
3) Everyone in the family is cooperative
4) We have a good communication within family
5) We are united
6) The love we have for one another make us strong
7) We do not give up for the sake of one another
8) We are proactive in dealing with the situation
9) We are practical in dealing with the situation
10) We have a pillar in the family and we follow his leadership
11) We redefine the meaning of the situation
12) We make the situation as normal as possible
13) We prepare for what might come
14) We believe in adopting a positive outlook
15) We pray to God
16) We believe in God
17) We control the negative emotions
18) We create a lighter mood in the family
19) We accept the situation

\section{Appendix 2}

Subjective Wellbeing Scale (Adapted from Chang, 2003)

1) I have the ability to cope with problems I faced.

2) I am happy.

3) I am accepted by the people around me.

4) I enjoy good emotional and mental well-being.

5) My family members are healthy and have a sense of well-being.

6) I am able to accept myself.

7) I have good health.

8) I have satisfying social relationships.

9) I am contented with what I have.

10) I am optimistic and positive.

11) I am having a balanced life.

12) I have my family support in the things I wanted to do.

13) I am satisfied with myself.

14) I have the freedom to do what I want.

15) I like to help others 


\section{Submit or recommend next manuscript to SCIRP and we will provide best service for you:}

Accepting pre-submission inquiries through Email, Facebook, Linkedin, Twitter, etc A wide selection of journals (inclusive of 9 subjects, more than 200 journals)

Providing a 24-hour high-quality service

User-friendly online submission system

Fair and swift peer-review system

Efficient typesetting and proofreading procedure

Display of the result of downloads and visits, as well as the number of cited articles

Maximum dissemination of your research work

Submit your manuscript at: http://papersubmission.scirp.org/ 